\title{
FEASIBILITY ASSESSMENT OF STIFF SEISMIC BASE ABSORBERS
}

\author{
Ioannis A. Antoniadis ${ }^{1}$, Konstantinos A. Kapasakalis ${ }^{2 *}$, and Evangelos J. Sapountzakis ${ }^{2}$ \\ ${ }^{1}$ Dynamics and Structures Laboratory, School of Mechanical Engineering, \\ National Technical University of Athens, Zografou Campus, GR-157 80 Athens, Greece \\ e-mail: antogian@central.ntua.gr \\ tel.: +30210-7721524; Fax.: +30210-7721525
}

\author{
${ }^{2}$ Institute of Structural Analysis and Antiseismic Research, School of Civil Engineering, \\ National Technical University of Athens, Zografou Campus, GR-157 80 Athens, Greece \\ e-mail: kostiskapasakalis@ hotmail.com, cvsapoun@central.ntua.gr \\ tel.: +30210-6082132, +30210-7721718; Fax.: +30210-7721720
}

\begin{abstract}
A radically new concept of a Stiff Seismic Base Absorber (SBA) is proposed. An inerter is first implemented, connecting directly the structure to the ground. This results to the decrease of the natural frequency of the structure, without the decrease of the structural stiffness. Parallel, an extension of the KDamper is used, in order to increase the apparent damping behavior of the inerter. A negative stiffness (NS) element connects the additional mass of the SBA to the structure and a positive stiffness element the additional mass to the base. Also, an artificial damper is placed in parallel with each stiffness element. The design of the SBA is based on an appropriate optimization approach, which includes the following novel features: i) the SBA foresees variation in all stiffness elements, ii) the optimal system parameters are selected based on engineering criteria with proper constraints and limitations to the system dynamic responses, iii) the earthquake input motion is selected according to the seismic design codes, iv) a displacementdependent non-linear configuration is proposed for the realization of the NS element, and v) the detuning phenomena are observed via sensitivity analysis. Compared to other vibration absorbers, the SBA presents a number of advantages. An improved superstructure dynamic behavior is observed combined with small base displacements, in the order of a few centimeters. The drastically reduced base displacements render the implementation of the SBA feasible using conventional structural elements. As a result, the SBA is a possible retrofitting option for seismic protection.
\end{abstract}

KEYWORDS: Seismic Protection; Negative Stiffness; Damping; KDamper; Inerter; Seismic Base Absorbers (SBA);

\section{INTRODUCTION}

During the latest years, seismic codes have significantly been altered with the intention to lead to resilient structures that perform better under seismic loads. To this end, seismic isolation has been one of the main approaches aiming to reduce structural seismic accelerations and, in this way, lead to earthquake-resistant design of building structures [1,2], bridges [3] and industrial facilities [4-6]. The concept of seismic isolation relies on a laterally flexible layer between the structure and its base. This way, the fundamental period of the system (base isolated) is significantly longer and thus the structural peak accelerations are reduced. A number of isolation devices from simple elastomeric bearings to more sophisticated roller bearings have been developed and advanced within the years. However, in order to isolate the building from its base, large displacements are required that are not always acceptable for numerous reasons, such as structural pounding, sensitivity in horizontal loads, proper connection for utilities, and more, that render this system inadequate for retrofitting.

These drawbacks have motivated the development of alternative control strategies combining conventional base isolation (BI) scheme with other active or passive control systems which, among others, include: (a) Tuned Mass Dampers (TMDs), (b) Inerters, (c) Negative Stiffness Devices (NSD) and "Quazi Zero Stiffness" (QZS) oscillators and (d) Negative Stiffness driven Absorbers/KDampers.

The concept of introducing additional masses (TMDs) has been employed in a variety of structural systems. Perhaps the most popular strategy is to implement the TMDs in the bases of structures [7-9] in order to reduce the displacement demand of base isolated systems. The main drawbacks of this approach are: i) the need of large additional masses, comparable to the mass of the structure itself, ii) the detuning of the TMD parameters and iii) the large TMD displacements [10], which in some cases exceed even the base displacements. 
A more effective alternative is a new passive vibration control technique combining the BI with a Tuned Mass Damper Inerter (TMDI) [11,12]. In this concept, the secondary mass of the TMD is supported to the ground by an ideal inerter [13]. The ideal inerter is a linear massless two-terminal mechanical element developing a resisting force proportional to the relative acceleration of its terminals with proportionality constant, "inertance", measured in mass (kg) unit. The overall structure behavior is improved, however, comparable with a high mass TMD or a highly damped base isolated system.

Quazi Zero Stiffness (QZS) or negative stiffness (NS) oscillators aim to significantly increase the natural period the system, as in the case of the conventional base isolation approaches. QZS and NS oscillators find numerous applications in seismic isolation [14-21]. The accelerations and inter-story drifts are simultaneously reduced by weakening the structure (reducing strength) and introducing additional damping. Even though weakening and damping of structures improve its dynamic behavior, it leads to early yielding resulting in damage, inelastic excursions, and permanent deformations.

A class of negative stiffness driven absorbers is based on increasing the effective damping of the system by the appropriate introduction of NS elements. Proposed by Antoniadis et al. [22], the KDamper exploits the advantages of the aforementioned concepts, incorporating appropriate stiffness and mass elements, which include a NS element. The KDamper has been examined for the protection of bridge structures [23-27], Wind Turbines [28,29] and structural systems [30,31]. In addition, the KDamper is effectively implemented as an Absorption Base (KDAB) in the bases of structures [32-37].

In this paper, a radically new concept of a Stiff Seismic Base Absorber (SBA) is proposed. An inerter is first implemented, connecting directly the structure to the ground. This results to the decrease of the natural frequency and the seismic load of the structure, without the decrease of the structural stiffness. Parallel, an extension of the KDamper concept (EKD) is used, in order to increase the apparent damping behavior of the inerter. A negative stiffness element connects the additional mass of the SBA to the structure and a positive stiffness element the additional mass to the base. Furthermore, a damping coefficient is placed in parallel to each stiffness element and an inerter is implemented between the structure and the base/ground. The design of the proposed passive vibration absorption concept is based on an appropriate optimization approach, which includes the following novel features:

i. $\quad$ The proposed system (SBA) foresees variation in all stiffness elements, for a more realistic design.

ii. The optimal system parameters are selected based on engineering criteria with proper constraints and limitations to the system dynamic responses.

iii. The earthquake input motion in the aforementioned optimization problem is selected according to the seismic design codes.

iv. A displacement-dependent non-linear configuration is proposed for the realization of the NS element, generating as far as possible linear stiffness.

v. The detuning phenomena are observed via sensitivity analysis.

Section 2 of the paper presents the proposed stiff seismic base absorber (SBA) that combines the extension of KDamper (EKD) with an inerter. The equations of motion are formed and the basic requirement regarding the free design variables of the system are presented. Section 3 presents the optimization problem from which the system parameters are selected. More specifically, section 3.1 presents the free design variables of the proposed vibration control strategy. The earthquake excitation input is selected according to the seismic design codes. More specifically, in section 3.2 artificial accelerograms are generated, compatible to the EC8 response spectra. These accelerograms are selected as earthquake input for the optimization problem which is subsequently presented in section 3.3 , where harmony search algorithm (HS) [38], a novel metaheuristic algorithm, is adopted. Finally, section 3.4 presents the optimization results. The dynamic performance of a SDoF system controlled with the SBA is evaluated in section 4 with real earthquake records. The proposed displacement-dependent configuration for the realization of the NS element is presented, and the non-linear behavior of the system is compared with the initially expected linear one. The effectiveness of the SBA in reducing the superstructure responses of a multi-story building structures is assessed in Section 5. The optimal design of the SBA is initially extended in MDoF structures. A 3-story building structure is assumed in which the SBA is implemented in its base. The effectiveness of the SBA is observed based on a comparison with: 1) a conventional base isolated system (BI), 2) a highly damped BI system (BI-HD), 3) a conventional BI system equipped with an inerter device (BI-I) and 4) an extended KDamper concept (EKD) implemented in the base. In section 6, an indicative design of the implemented SBA devices is presented. Section 7 summarizes the main findings of this research work. 
The essential features of the SBA implemented in a SDOF and a multi-story building structure, as compared to the previously mentioned controlled systems, are summarized as follows:

i. The results of the non-linear problem are equivalent to the initial linear one, used for the design.

ii. The system dynamic performance is not vulnerable to detuning.

iii. The controlled SDoF system's relative displacements is significantly low, compared to a highly damped base isolated system, in all the range of structure maximum absolute accelerations.

iv. The floor accelerations and inter-story drifts of the examined multi-story building are significantly reduced, while at the same time the base displacement is in the order of a few centimeters.

v. The small base displacement of the SBA with high $A F=70 \%$ (acceleration filter), renders the implementation of the proposed device feasible using conventional structural elements, without the need of special type of bearings. As a consequence, retrofitting is possible.

vi. The design of the SBA devices is realistic and within reasonable technological capabilities.

\section{Notation}

In the matrix-vector notation, boldface lowercase and capital variables denote vectors and matrices, respectively. A superimposed dot denotes the derivative with respect to time, i.e. $\dot{u}=\mathrm{d} w \mathrm{~d} t$ and $\ddot{\mathrm{u}}=\mathrm{d}^{2} u / \mathrm{d} t^{2}$ and the superscript $T$ applied to vectors and matrices is the transpose operator. Other symbols will be defined in the text at their first appearance.

\section{UNDERLYING DYNAMIC CONCEPTS AND INHERENT DYNAMIC CONSTRAINTS}

\subsection{Dynamic properties and inherent constraints of existing base vibration absorption concepts}

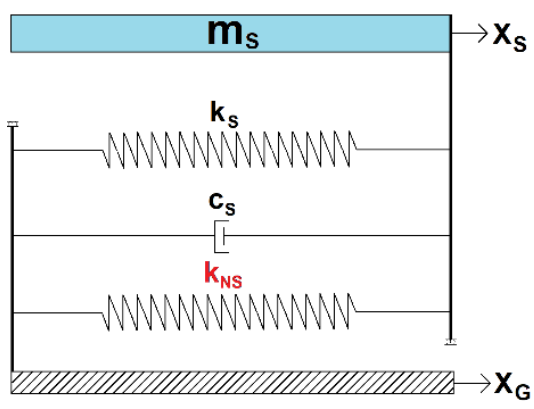

(A)

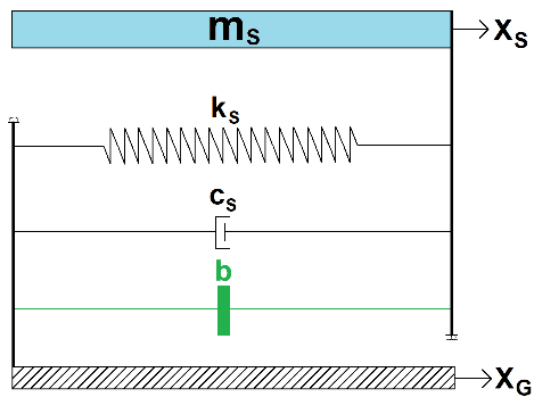

(B)

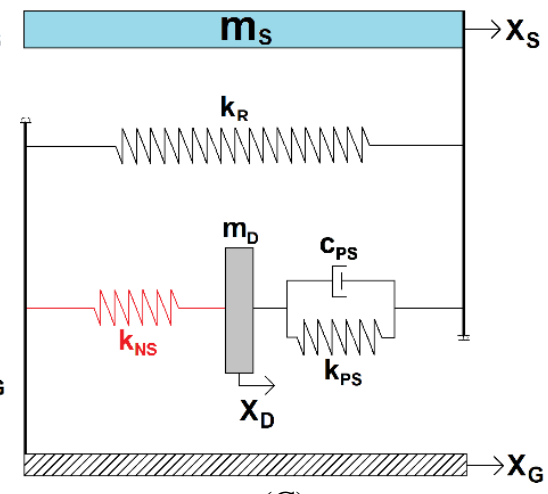

(C)

Figure 1. Three vibration control systems: (A) Negative Stiffness (NS) isolator, (B) Inerter and (C) KDamper concept.

Figure 1, illustrates the fundamental layout of various vibration isolation and damping concepts described in the literature and presented herein to facilitate the understanding of the KDamper concept. All strategies aim to minimize the response $X_{S}(t)$ of a low-damped (or undamped) SDoF comprising a mass $m_{S}$ and static stiffness $k_{S}$ due to the resulting motion of a base excitation $X_{G}(t)$. The concept of the QZS oscillator, presented in Figure 1.A, is to add a negative stiffness (NS) element $k_{N}$ in parallel to the initial stiffness $k_{S}$. The equation of motion of the QZS oscillator becomes:

$$
m_{S} \ddot{u}_{S}+c_{S} \dot{u}_{S}+\left(k_{S}+k_{N}\right) u_{S}=m \ddot{u}_{S}+c_{S} \dot{u}_{S}+k_{Q Z S} u_{S}=-m_{S} \ddot{X}_{G}
$$

where $u_{S}=X_{S}-X_{G}$. Since $k_{N}$ is negative, the overall static stiffness of the system is reduced, $k_{Q Z S}=k_{S}+k_{N S}$. This limits the static loading capacity and correspondingly increases the natural period of the system. Accordingly, the system attracts lower lateral seismic forces and develops reduced peak accelerations. Alternatively, the addition of an inerter manages to increase the natural period of the system, and as a consequence reduce the seismic load, without having to reduce the static stiffness of the structure or increase its actual mass. This configuration of the inerter is presented in Figure 1. $\mathrm{B}$, and the equation of motion is: 
$\left(m_{S}+b\right) \ddot{u}_{S}+c_{S} \dot{u}_{S}+k_{S} u_{S}=-m_{S} \ddot{X}_{G}$

Figure 1.C presents the fundamental concept of KDamper, first introduced in Antoniadis et al. [22]. Similar to the QZS oscillator, it uses a NS element $k_{N}$. However, contrary to the QZS, the overall static stiffness of the system is maintained positive and, in this way, the risk of potential instability is eliminated. The total stiffness of the system with the KDamper can be expressed using the following formula:

$k_{R}+\frac{k_{P S} k_{N S}}{k_{P S}+k_{N S}}=k_{S}=\left(2 \pi f_{0}\right)^{2} m_{\text {total }}$

Compared to the TMD or the TMDI (TMD with grounded inerter), the KDamper uses an additional NS element $k_{N}$, which connects the oscillating mass of the KDamper to the base. As a result, the equations of motion of the KDamper system becomes:

$\mathbf{M} \ddot{\mathbf{u}}(t)+\mathbf{C} \dot{\mathbf{u}}(t)+\mathbf{K u}(t)=-\tau \ddot{X}_{G}(t)$

$\mathbf{M}=\left[\begin{array}{cc}m_{S} & 0 \\ 0 & m_{D}\end{array}\right] ; \mathbf{K}=\left[\begin{array}{cc}k_{R}+k_{P S} & -k_{P S} \\ -k_{P S} & k_{N S}+k_{P S}\end{array}\right] ; \mathbf{C}=\left[\begin{array}{cc}c_{P S} & -c_{P S} \\ -c_{P S} & c_{P S}\end{array}\right] ; \boldsymbol{\tau}=\left[\begin{array}{l}m_{S} \\ m_{D}\end{array}\right] ; \mathbf{u}(t)=\left[\begin{array}{l}u_{S}(t) \\ u_{D}(t)\end{array}\right]$

where $u_{D}=X_{D}-X_{G}$.

In order to observe the dynamic behavior of the aforementioned vibration absorption concepts, they are implemented in a SDoF system of mass $m_{S}$, initial static stiffness $k_{s}$, damping ratio $5 \%$ and natural frequency $f_{S}=1 \mathrm{~Hz}$. The QZS oscillator and the inerter configuration reduce the natural frequency of the system to $0.4 \mathrm{~Hz}$.

The design of KDamper follows the procedure described in Kapasakalis et al. [37], for optimal acceleration response, and is implemented as a stiff vibration absorber with a nominal frequency of $1 \mathrm{~Hz}$. The Transfer Functions of the system responses, i.e. the absolute acceleration $H_{A S}$ and relative displacement $H_{U S}$ are presented in Figure 2.

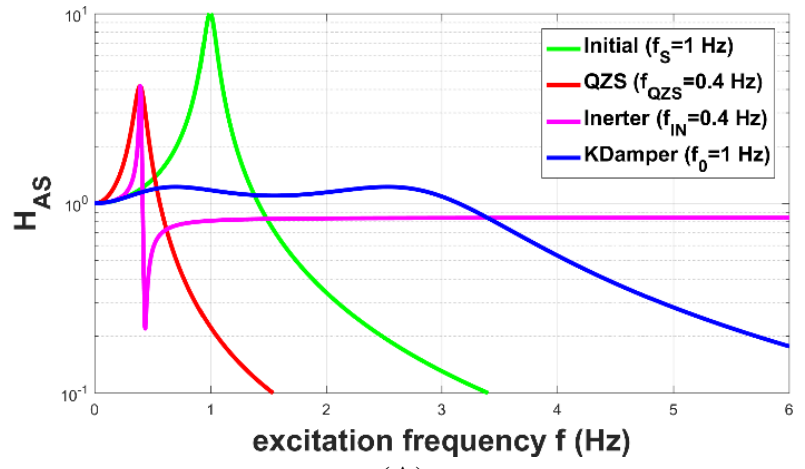

(A)

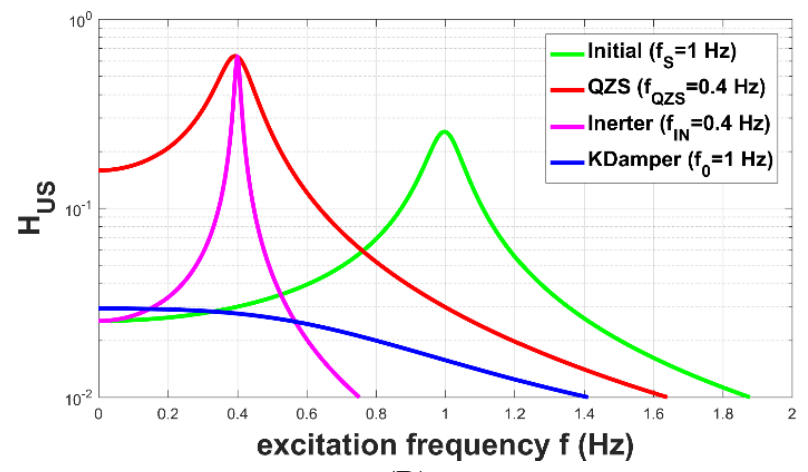

(B)

Figure 2. Transfer Functions of the initial and the considered controlled systems. (A) absolute acceleration $H_{A S}$ and (B) relative displacement $H_{U S}$.

It is observed that the inerter manages to reduce the natural frequency $f_{0}$, as in the case of the QZS oscillator, without having to reduce the stiffness of the system (Figure 2.B) or increase the seismic load (Figure 2.A). However, in both cases (inerter, QZS), the effective damping of the system is reduced (Figure 2.B). On the other hand, the KDamper manages to greatly reduce the peak of the transfer functions $H_{A S}$ and $H_{U S}$, simultaneously, and therefore increase the effective damping of the system. At the same time, the structure relative displacement transfer function $H_{U S}$ is significantly low in all the excitation frequency range. However, since the KDamper is implemented as a stiff vibration absorber, the acceleration response of the system retains a significant frequency content. 


\subsection{The proposed stiff seismic base absorber (SBA)}

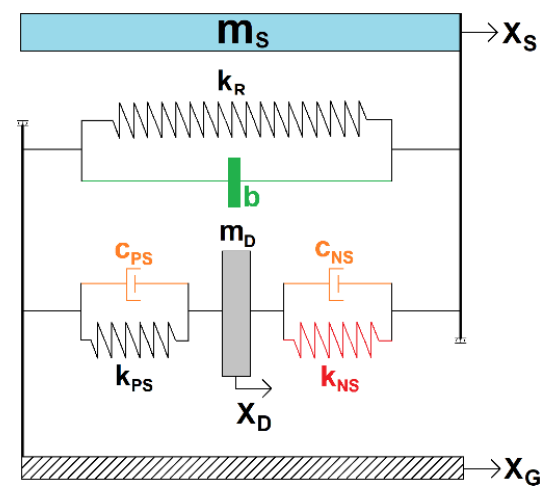

Figure 3. Proposed stiff seismic base absorber (SBA), that combines an extension of KDamper with an inerter.

In this paper, a stiff seismic base absorber (SBA) is proposed, as presented in Figure 3. The SBA combines the inerter with an extension of the KDamper (EKD) concept. The inerter is implemented in order to reduce the natural frequency $f_{0}$ of the system. At the same time, the extended KDamper is used to control the large required structure relative displacements by the increase of the effective damping of the system.

Compared to the KDamper, the NS element $k_{N S}$ connects the additional mass $m_{D}$ to the structure, instead of the positive stiffness element $k_{P S}$, which now connects the $m_{D}$ to the base. Furthermore, a damping coefficient is placed in parallel to each stiffness element, $k_{N S}$, and $k_{P S}$. Finally, the inerter coefficient, $b$, connects the structure directly to the base, as in the aforementioned configuration of the inerter. The matrices and vectors entering Equation (4) are defined as:

$\mathbf{M}=\left[\begin{array}{cc}m_{S}+b & 0 \\ 0 & m_{D}\end{array}\right] ; \mathbf{K}=\left[\begin{array}{cc}k_{R}+k_{N S} & -k_{N S} \\ -k_{N S} & k_{N S}+k_{P S}\end{array}\right] ; \mathbf{C}=\left[\begin{array}{cc}c_{N S} & -c_{N S} \\ -c_{N S} & c_{N S}+c_{P S}\end{array}\right] ; \boldsymbol{\tau}=\left[\begin{array}{l}m_{S} \\ m_{D}\end{array}\right] ; \mathbf{u}(t)=\left[\begin{array}{l}u_{s t}(t) \\ u_{D}(t)\end{array}\right]$

\section{OPTIMAL SELECTION OF THE SBA PARAMETERS}

\subsection{Free design variables}

As mentioned in the previous section, the stiffness parameters of the KDamper, and SBA respectively, are selected according to Equation (3) in order to maintain the total stiffness of the system. However, variation in the absolute values of the stiffness elements $k_{N S}, k_{P S}$ and/or $k_{R}$, may endanger the static stability of the structure. In order to ensure that potential loss of the static stability is prevented, the possible variations of $k_{N S}, k_{P S}$ and $k_{R}$ should be taken into consideration in the design and optimization of the SBA parameters. The stiffness parameters of the system may present significant fluctuations due to numerous reasons, such as temperature variations, manufacturing tolerances, or non-linear behavior of structural elements. Consequently, an increase of the absolute value of $k_{N S}$ and/or a decrease of the values of $k_{P S}$ and $k_{R}$ by a factor $\varepsilon_{N S}, \varepsilon_{P S}$ and $\varepsilon_{R}$, respectively, may result in the system being unstable. This situation may happen in the following case:

$$
\left(1-\varepsilon_{R}\right) k_{R}+\frac{\left(1-\varepsilon_{P S}\right) k_{P S}\left(1+\varepsilon_{N S}\right) k_{N S}}{\left(1-\varepsilon_{P S}\right) k_{P S}+\left(1+\varepsilon_{N S}\right) k_{N S}}=0
$$

As a consequence, the stiffness elements, $k_{P S}$ and $k_{R}$, result from Equations $(3,7)$ as a function of the nominal SBA frequency, $f_{0}$, and the value of the NS element $k_{N S}$. Assuming that the additional mass, $m_{D}$ and the stability factors $\varepsilon_{N S}$, $\varepsilon_{P S}$ and $\varepsilon_{R}$ are given for a specific design, the unknown parameters of the system are: 1) the nominal SBA frequency $\left.f_{0}, 2\right)$ the value of the NS element $\left.k_{N S}, 3,4\right)$ the damping coefficients $c_{N S}$ and $c_{P S}$ and 5) the inerter coefficient $b$. The SBA is designed according to seismic design codes, as presented in section 3.2. The constraints that relate to the system responses and the limits of the free design variables are based on engineering criteria and are described in section 3.3, where linear analysis is considered. For the optimization process, the harmony search algorithm is adopted [38]. 


\subsection{Earthquake excitation input}

The calculation of the structural displacement, velocity and acceleration due to seismic excitations is usually undertaken according to seismic design codes (e.g. EC8) and the design response spectrum. As a consequence, the seismic intensity measures are within specified limits for a system with given properties (fundamental structural period and damping ratio) and ground conditions. However, the application of such approaches and the use of the code's Design Response Spectra for the selection of the SBA parameters, is not considered adequate, since the controlled system with the SBA has multiple eigenfrequencies. Therefore, analysis in the time-domain is necessary for the optimal selection of the SBA parameters.

In this section, a presentation of the details regarding the generation of artificial accelerograms based on the design response spectra is undertaken. For the purposes of this study, the approach followed is based on generating a sample of artificial accelerograms with acceleration response spectra in accordance with the EC8 design response spectra. Artificial, spectrum-compatible accelerograms are generated using the SeismoArtif Software [39]. In this paper, the artificial accelerograms are designed to match the EC8 response spectra incorporating the following seismic properties: ground type C, spectral acceleration $0.36 \mathrm{~g}$, spectrum type I and importance class II. A sample of 30 artificial accelerograms, with a mean PGA of $5.19 \mathrm{~m} / \mathrm{sec}^{2}$ is generated and plotted in Figure 4.B along with the EC8 response spectrum for comparison with the design guidelines. An accurate match is observed (percentage deviation less than $10 \%$ ) in the range of periods from 0.2 to $2 \mathrm{sec}$, which are considered relevant for the structural performance.

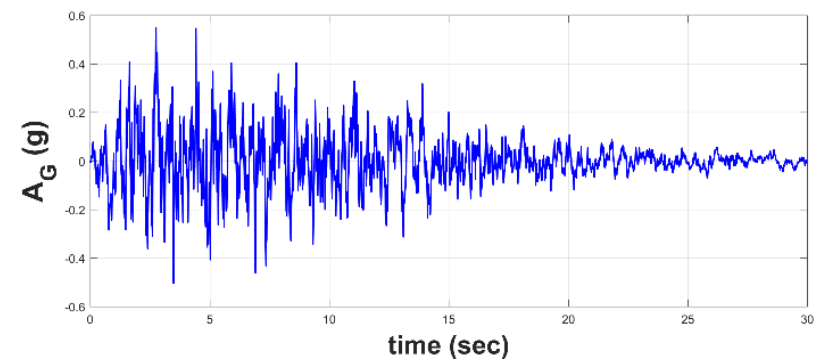

(A)

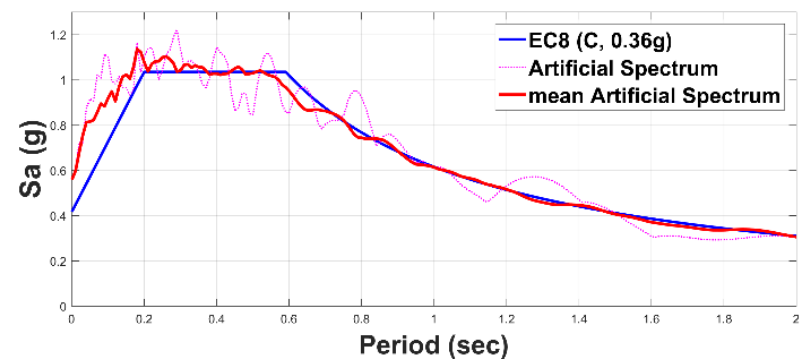

(B)

Figure 4. (A) Artificial Accelerogram and (B) Mean Artificial acceleration response spectrum of the 30 generated artificial accelerograms compared to the EC8 acceleration response spectrum.

\subsection{Optimization constraints and limitations based on engineering criteria}

The given parameters of the SBA are the additional mass $m_{D}$ and the stability factors $\varepsilon_{N S}, \varepsilon_{P S}$, and $\varepsilon_{R}$. The free design variables sough in the optimization problem are: 1) the nominal SBA frequency $f_{0}, 2$ ) the NS element value $k_{N S}, 3,4$ ) the damping coefficients $c_{N S}$ and $c_{P S}$ and 5) the inerter coefficient, $b$. The structure relative to the base displacement is set as the objective function. In order for the proposed vibration control strategy to be efficient and realistic, the constraints that refer to the structural dynamic responses and the limits of the free design variables must be engineering-criteria based. In particular:

i. An acceleration filter (AF) is placed as a constraint for the structure absolute acceleration, expressed as a percentage of the mean PGA.

ii. The NS element stroke $\left(X_{S-D}\right)$ is set as a constraint, with an upper limit that of $12 \mathrm{~cm}$, which based on the previous work of Kapasakalis et al. [36] proves to be a realistic value for the design of the negative stiffness element with pre-compressed springs.

iii. According to previous work of KDamper [32-37], an additional mass of 5\% is efficient. In an effort to make the device more realistic and easier to implement, $m_{D}$ is selected as $0.1 \%$ of the structure mass.

iv. The stability factors $\varepsilon_{N S}, \varepsilon_{P S}$, and $\varepsilon_{R}$ are selected equal to $10 \%$.

v. The damping coefficients $c_{N S}$ and $c_{P S}$ upper limit is $600 \mathrm{kNs} / \mathrm{m}$. Common linear damping devices can be used.

vi. The nominal SBA frequency $f_{0}$ varies in the range $[0.151 .5](\mathrm{Hz})$.

vii. The NS element absolute maximum value is set as $|-15000| \mathrm{kN} / \mathrm{m}$, which based on previous indicative designs of the NS element realized with pre-compressed springs, [22] and [36] (in Greek), for $m_{t o t}=300 \mathrm{tn}$ is a realistic value (50\% lower compared to [36]). 


\subsection{Optimization results}

The addition of the inerter, that connects the structure directly to the base, aims to reduce the nominal frequency $f_{0}$ of the EKD. The inerter, $b$ is expressed as a $\%$ of the structure mass, $m_{S}$. In order to observe its effectiveness to the system responses, 3 cases regarding the implementation of the inerter are considered. In the first case, only the EKD is considered $\left(b_{\max }=0\right)$. In the second and third cases, the SBA's maximum inerter coefficient is $b_{\max }=1(100 \%)$ and 2 (200\%) respectively. Figure 5 presents these 3 optimized test cases. It is observed that the addition of the inerter manages to greatly reduce the structure relative displacement and NS element stroke in all the range of the Acceleration Filter. The increase of the upper limit of $b$ over than 1 , does not improve the dynamic structural behavior.

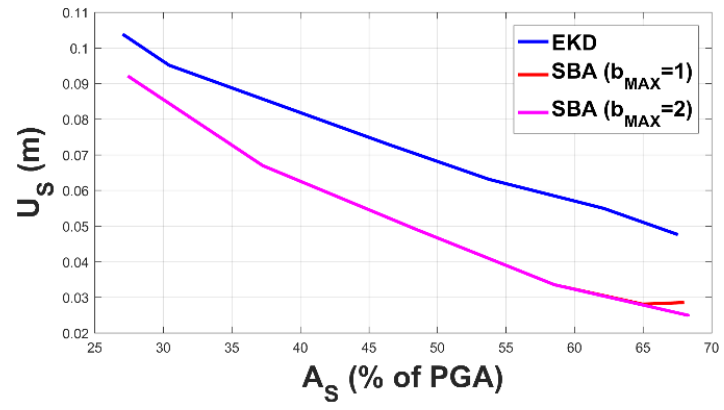

(A)

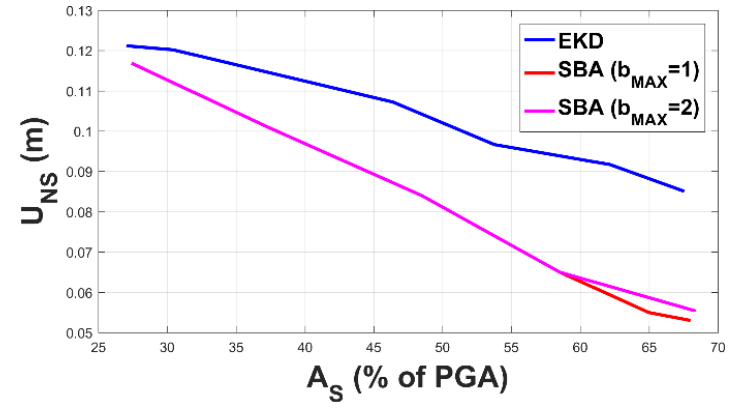

(B)

Figure 5. (A) Structure relative displacement and (B) NS element stroke (mean of 30 max) over the structure absolute acceleration (\% of the mean PGA) of the SBA with various values of the upper limit of the inerter.

The performance of the SBA- $A F$ is compared with the previous optimal design of KDamper, as presented in [37]. For this reason, two sets of parameters of each concept, that present similar results, in terms of the structure's dynamic responses, are selected and compared in Table 1. It is observed that the SBA $\left(b_{\max }=1\right)$ manages to reduce the structure relative displacement and the NS element stroke, at the same time, in all the range of the imposed acceleration filter $(A F)$, as compare with the previously optimized KDamper presented in [37] and the EKD with the same limitations and constraints as the SBA. Finally, the transfer functions of the SBA-30,50 and 70 are presented in Figure 6 and are compared with a highly damped base isolation system with a damping ratio of $20 \%$ (BI-HD).

Table 1. Comparison of the KDamper, designed in Kapasakalis et al. [37] and SBA system proposed in this paper.

\begin{tabular}{|c|c|c|c|c|c|c|}
\hline$\#$ & Examined system & $A_{S}\left(\mathrm{~m} / \mathrm{sec}^{2}\right)$ & $A_{S}(\%$ of PGA $)$ & $U_{S}(m)$ & $U_{N . S .}(m)(\mathrm{NS} \mathrm{Stroke})$ & $\varepsilon_{i}(\%)$ \\
\hline \multirow{4}{*}{ Set \#1 } & KDamper in [37] & 2.085 & 40.2 & 0.093 & 0.363 & $\varepsilon_{N S}=5$ \\
\cline { 2 - 8 } & SBA-30 $(b=0) /$ EKD & 1.579 & 30.4 & 0.0951 & 0.1202 & $\varepsilon_{N S, P S, R}=10$ \\
\cline { 2 - 8 } & SBA-30 $\left(b_{\max }=1\right)$ & 1.934 & 37.3 & 0.0669 & 0.1011 & $\varepsilon_{N S, P S, R}=10$ \\
\hline \multirow{3}{*}{ Set \#2 } & KDamper in [37] & 3.692 & 71.1 & 0.0379 & 0.163 & $\varepsilon_{N}=5$ \\
\cline { 2 - 8 } & SBA-70 $(b=0) /$ EKD & 3.225 & 62.1 & 0.0549 & 0.0917 & $\varepsilon_{N S, P S, R}=10$ \\
\cline { 2 - 8 } & SBA-70 $\left(b_{\max }=1\right)$ & 3.372 & 65.0 & 0.0281 & 0.055 & $\varepsilon_{N S, P S, R}=10$ \\
\hline
\end{tabular}

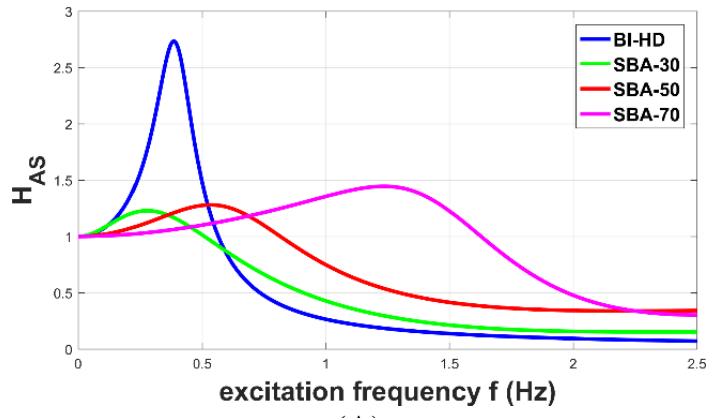

(A)

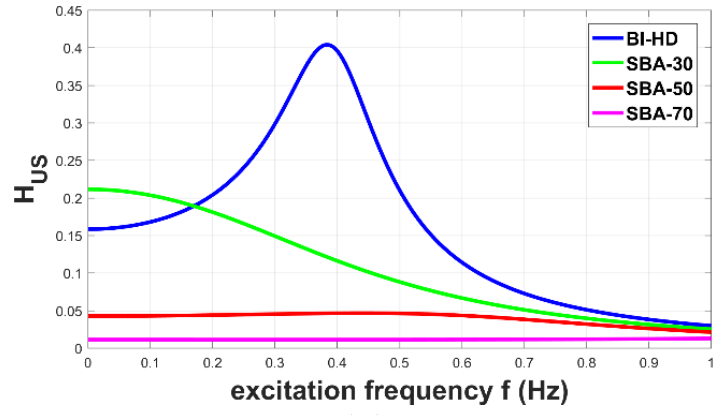

(B)

Figure 6. Transfer Functions of the SBA-30, 50 and 70 systems compared with a highly damped base isolated one (BI-HD). (A) absolute acceleration $H_{A S}$ and (B) relative displacement $H_{U S}$. 


\section{SDOF DYNAMIC PERFORMANCE CONTROLLED WITH NON-LINEAR NEGATIVE STIFFNESS SEISMIC BASE ABSORBERS (SBA)}

Almost all NS designs result from unstable non-linear configurations. Furthermore, real earthquake excitations are non-stationary with random duration. Therefore, the effectiveness of the proposed base absorber (SBA) should be examined also with real earthquake records, considering a realistic displacement-dependent non-linear configuration for the realization of the NS element. The selection of the NS element's set-up requires the solution of a linear problem first in order to estimate the maximum absolute displacement values that are necessary for the design, as described in section 3 for the optimal SBA parameters. The real earthquake excitations selected in this paper are 12 near and 12 far fault earthquake records that are known to have had devastating impact on structural systems. Specific details of the proposed non-linear configuration are found in section 4.1 and the non-linear dynamic responses of the controlled system are presented in section 4.2 using the Newmark- $\beta$ method with linear accelerations.

\subsection{Proposed displacement-dependent configuration for the realization of the NS element}

Based on the proposed configuration for the realization of the NS element in Antoniadis et al. [22], with precompressed springs, an alternative mechanism is hereby described, as depicted in Figure 7. The NS spring $k_{N}$ is realized by a linear vertical spring with constant $k_{H}$, which connects the mass $m_{D}$ and the structure by an articulated mechanism. Further information regarding the geometrical parameters presented in Figure 7.B, can be found in [22], the selection of which follows the procedure described also in [22]. The NS stiffness produced by the linear precompressed vertical spring, $k_{H}$, is given by:

$$
k_{N S}=\frac{\partial f_{N}}{\partial u_{N S}}=-k_{H}\left[1+c_{I} \frac{1}{\left(1-u_{N S}^{2} / a^{2}\right)^{3 / 2}}\right]
$$

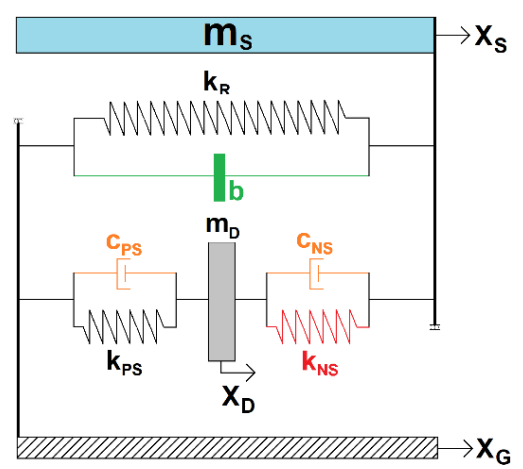

(A)

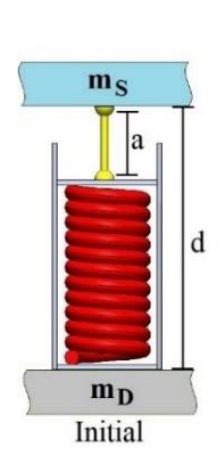

nitial

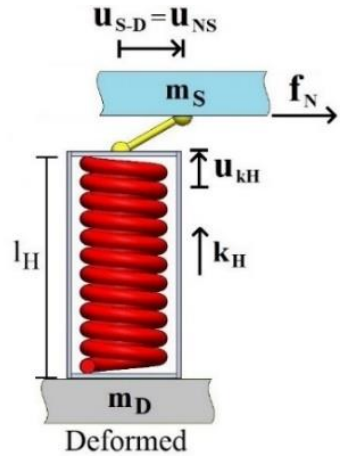

(B)

Figure 7. Schematic representation (A) of the SBA and (B) of the proposed displacement-dependent configuration for the realization of the NS element.

\subsection{Dynamic Responses}

In order to observe the efficiency of the SBA, it is compared with 2 base isolated systems. The first one is a conventional base isolated system with a damping ratio of $5 \%$ and will be referred hereafter as BI, the second one is a highly damped BI with an increased damping ratio of $20 \%$ and will be referred hereafter as BI-HD. The considered base isolated systems have a base natural frequency equal to $0.4 \mathrm{~Hz}$.

Figure 8 presents the system dynamic responses of all the examined control systems and considered earthquake excitations. Figure 9 presents comparative results between a conventional base isolated system (BI) and the SBA-30 system, considering linear NS and non-linear NS with the proposed configuration proposed in section 4.1, for the L'Aquila earthquake excitation. The SBA retains the structure absolute acceleration at comparable levels with the BI, while the structure relative displacement is reduced by more than $60 \%$. Finally, it is observed that the dynamic responses of the proposed displacement-dependent non-linear configurations are in a very good agreement to that of the initial linear system previously solved. 

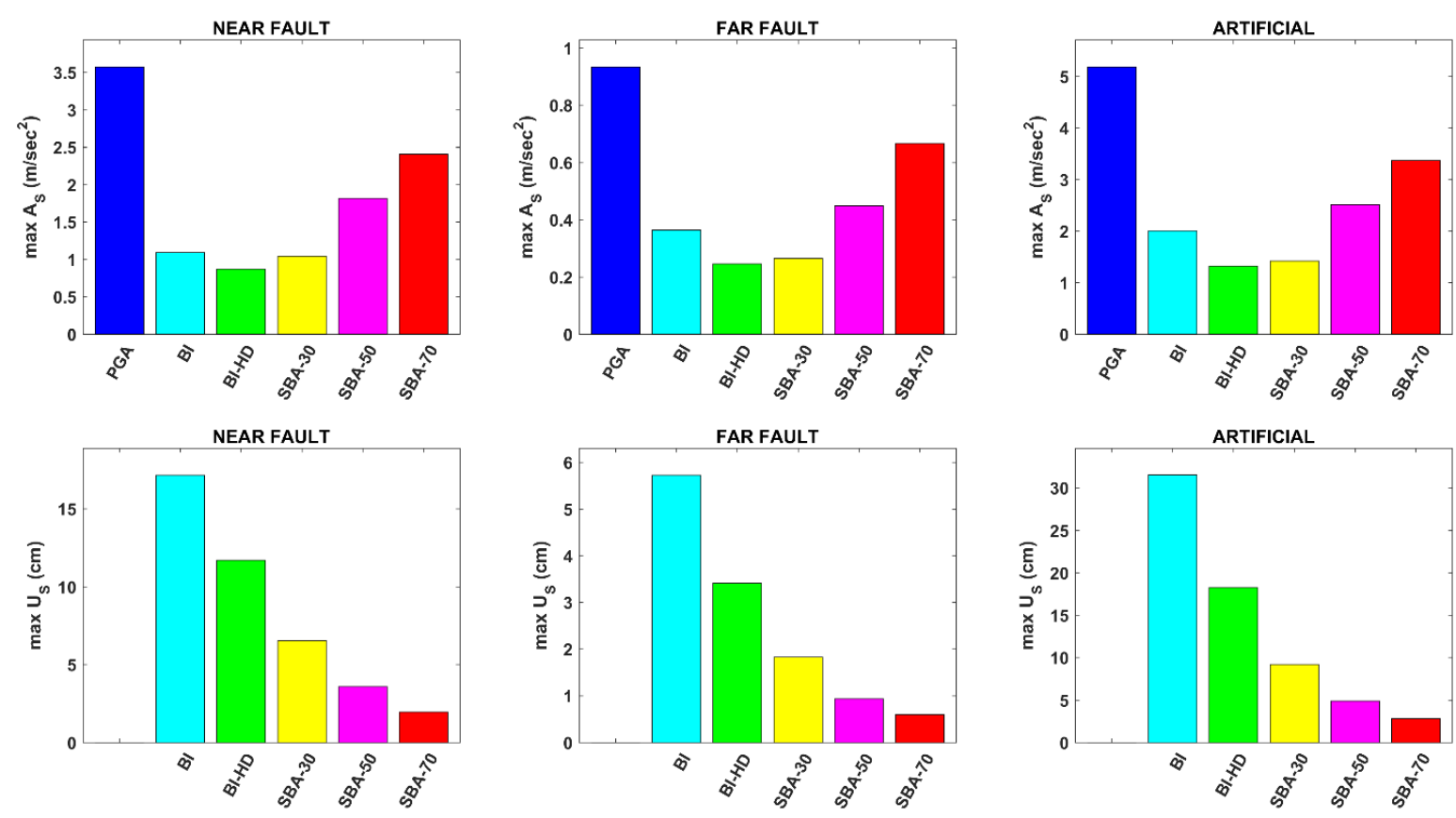

Figure 8. Dynamic responses (mean of maximum values) of all the earthquake motions selected in this paper, 12 Near and Far fault records and 30 Artificial Accelerograms, of all the considered systems, BI, BI-HD, SBA-70.

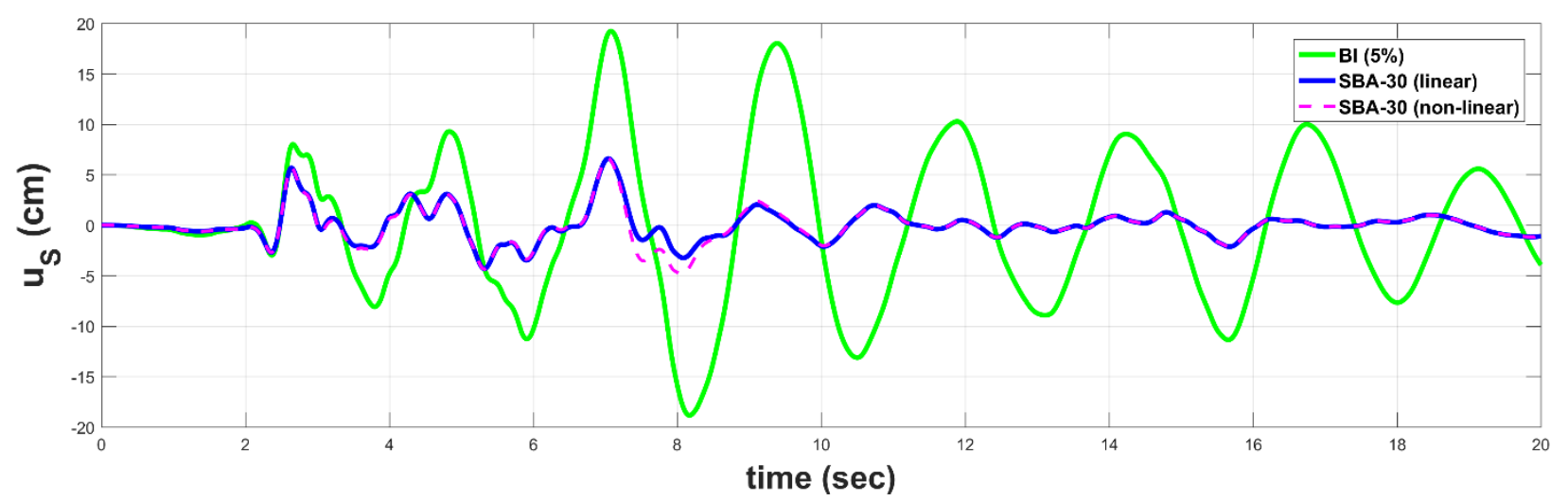

(A)

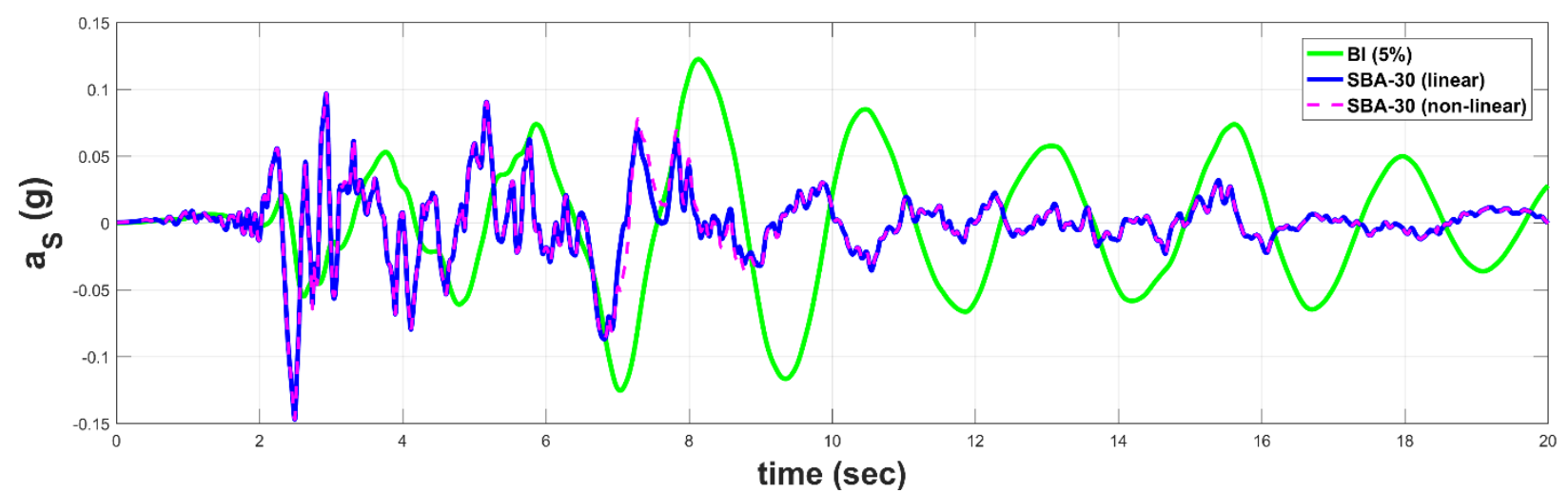

(B)

Figure 9. Dynamic responses of the SBA-30 system, considering linear NS and non-linear NS with the proposed configuration proposed in section 4.2, compared with a conventional base isolated system, for the L'Aquila earthquake excitation. (A) Structure relative displacement $u_{S}$ and (B) structure absolute acceleration $a_{S}$. 


\section{ASSESSMENT OF THE OPTIMAL SBA PARAMETERS FOR SEISMIC PROTECTION OF MULTISTORY BUILDINGS}

In this section, the proposed control strategy (SBA) is extended for possible implementation in MDoF structural systems. The optimal SBA parameters are selected according to the methodology proposed in section 3. In order to examine the efficiency of the SBA, the controlled system is subjected to artificial accelerograms and real earthquake records, presented in section 3 and 4 respectively, and is compared with 3 cases of base isolated systems. In section 5.1 the extension of the SBA design methodology to MDoF systems is presented, in section 5.2 the numerical application is performed, and in section 5.3 the detuning phenomena are observed via sensitivity analysis.

\subsection{Extension of the optimal SBA design to MDoF structural systems}

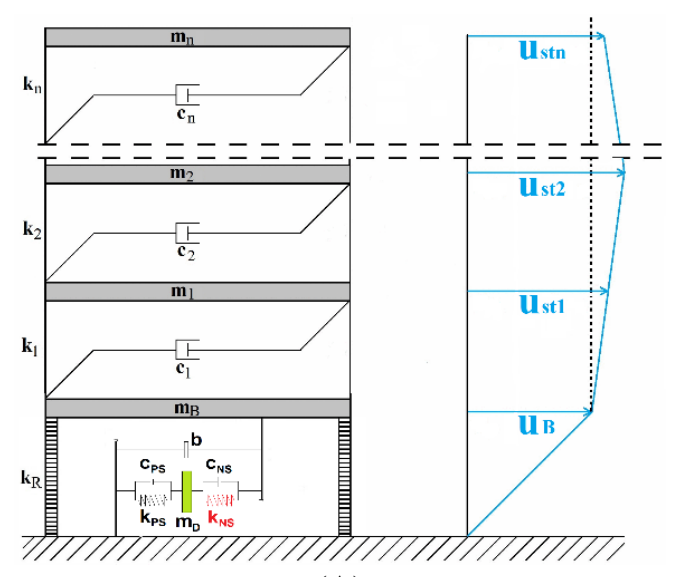

(A)

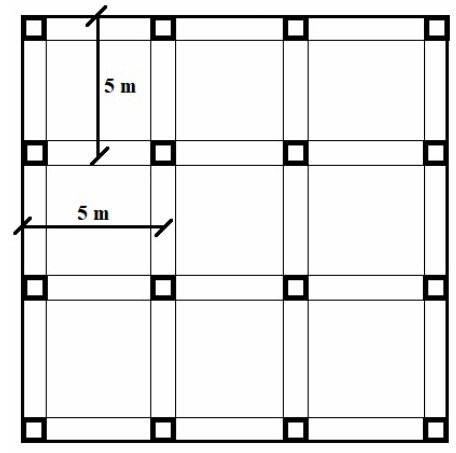

(B)

Figure 10. (A) Multi-story building with the proposed stiff seismic base absorber system, SBA (sketch of the model) and (B) typical ground floor plan of the structure.

The proposed stiff seismic base absorber, SBA, is implemented in the bases of multi-story building structures, as illustrated in Figure 10.A. Regarding the modeling of the superstructure, it is assumed that: the dynamic DoFs are collected in the array $\mathbf{u}_{\mathbf{s t}}(t)=\left[u_{s t l}(t), u_{s t 2}(t), \ldots, u_{s t n}(t)\right]^{T}$, where $u_{s t i}$ represents the relative to the ground displacement of the $i^{\text {th }}$ floor, the superstructure response is considered elastic and the SSI (soil structure interaction) effects are ignored.

Taking into consideration the aforementioned assumptions, the equations of motion, Equation (4), involve matrices with dimensions $(n+2) \times(n+2)$, which are defined as:

$$
\begin{aligned}
\mathbf{K}_{(n+2) \times(n+2)} & =\left[\begin{array}{ccc}
\mathbf{K}_{\mathbf{s}, n \times n} & \mathbf{0}_{n \times 1} & \mathbf{0}_{n \times 1} \\
\mathbf{0}_{1 \times n} & k_{N S}+k_{R} & -k_{N S} \\
\mathbf{0}_{1 \times n} & -k_{N S} & k_{P S}+k_{N S}
\end{array}\right] ; \mathbf{C}_{(n+2) \times(n+2)}=\left[\begin{array}{ccc}
\mathbf{C}_{\mathbf{s}, n \times n} & \mathbf{0}_{n \times 1} & \mathbf{0}_{n \times 1} \\
\mathbf{0}_{1 \times n} & c_{N S} & -c_{N S} \\
\mathbf{0}_{1 \times n} & -c_{N S} & c_{N S}+c_{P S}
\end{array}\right] ; \mathbf{u}_{(n+2) \times 1}(t)=\left[\begin{array}{c}
\mathbf{u}_{\mathbf{s t}}(t) \\
u_{B}(t) \\
u_{D}(t)
\end{array}\right] \\
\mathbf{M}_{(n+2) \times(n+2)} & =\left[\begin{array}{ccc}
\mathbf{M}_{\mathbf{S}, n \times n} & \mathbf{0}_{n \times 1} & \mathbf{0}_{n \times 1} \\
\mathbf{0}_{1 \times n} & m_{B}+b & 0 \\
\mathbf{0}_{1 \times n} & 0 & m_{D}
\end{array}\right] ; \boldsymbol{\tau}_{(n+2) \times 1}=\left[\begin{array}{c}
\mathbf{M}_{\mathbf{S}} \mathbf{1}_{n \times 1} \\
m_{B} \\
m_{D}
\end{array}\right] ; m_{S, t o t}=m_{B}+\sum_{i=1}^{n} m_{i}
\end{aligned}
$$

The matrices of mass, $\mathbf{M}_{\mathbf{s}}$, damping, $\mathbf{C}_{\mathbf{s}}$, and stiffness, $\mathbf{K}_{\mathbf{S}}$ refer to the original fixed-base superstructure (n-story building). The optimal SBA parameters are selected according to section 3, where $m_{S}$ now refers to the total mass of the system $m_{S, t o t}$, Equation (9). The inerter is expressed as a $\%$ of the total superstructure mass $m_{S, \text {,tot. }}$.

\subsection{Numerical application on a 3-story building}

A numerical case study has been conducted considering a 3-story typical residential building. The structural system's dynamic DoF are represented by the relative to the ground displacements of the 3-stories. The elastic modulus of 
reinforced concrete (assuming long-term cracked conditions) is equal to $E=26 \mathrm{GPa}$. The mass of the building is considered to be concentrated at the floor levels, with $m_{i}=80$ tn denoting the mass of the 3 stories, while the columns are assumed to be weightless. Rayleigh damping is assumed (mass and stiffness proportional) with $\zeta_{S i}=0.02$. A $15 \times 15 \mathrm{~m}$ floor plan-view has been considered with $0.3 \times 0.3 \mathrm{~m}$ square columns. According to performed modal analysis, the natural periods of the original structure are: $T_{S i}[\mathrm{sec}]=[0.495,0.177,0.122]$. The mass of the base is equal to 60 $t n$ and the additional mass $m_{D}$ is selected equal to $0.1 \%$ of the $m_{S, t o t}: 0.1 \% m_{S, t o t}=0.1 \%(60+3 \times 80)=0.3 \mathrm{tn}$.

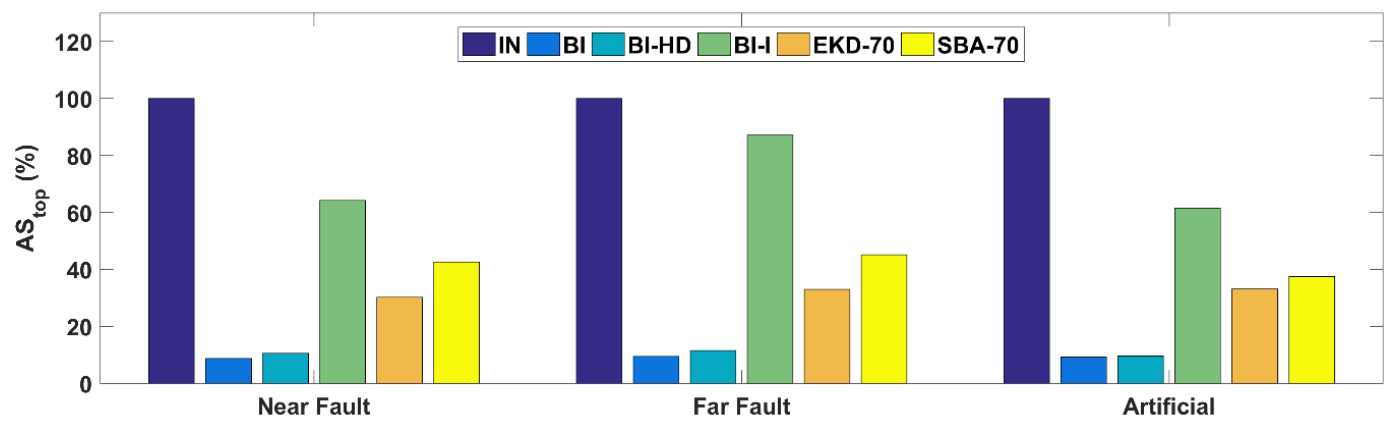

(A)

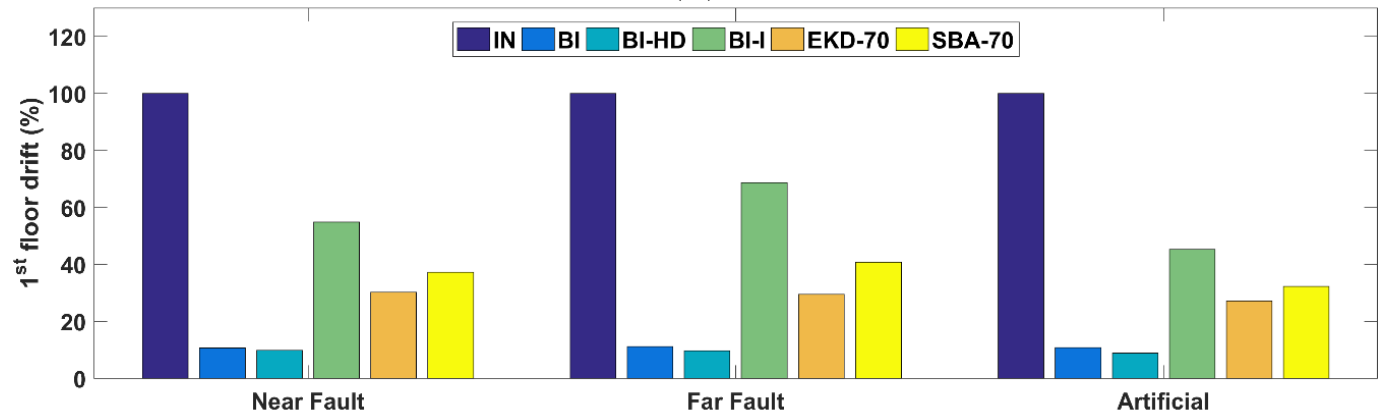

(B)

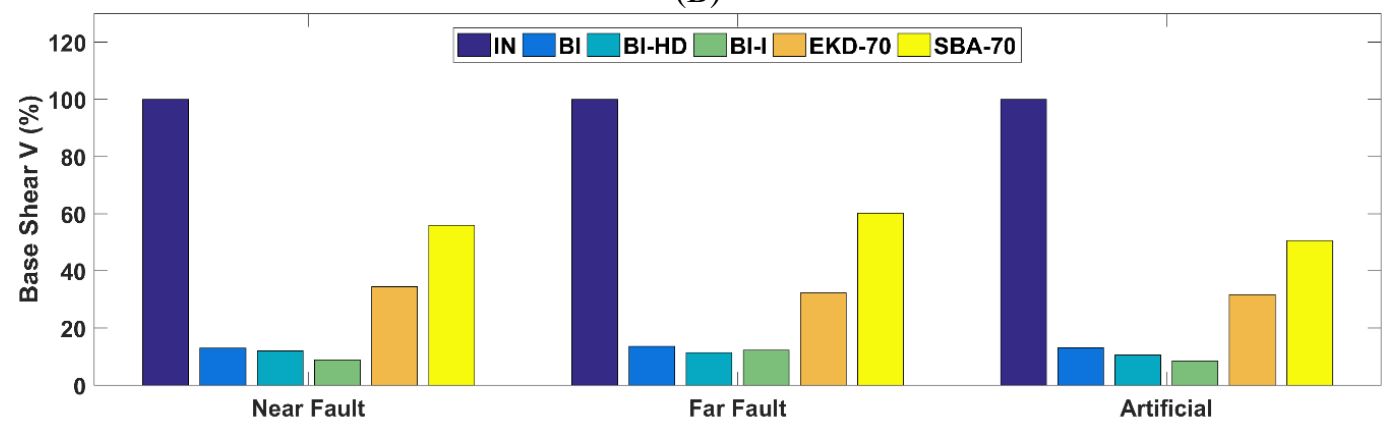

(C)

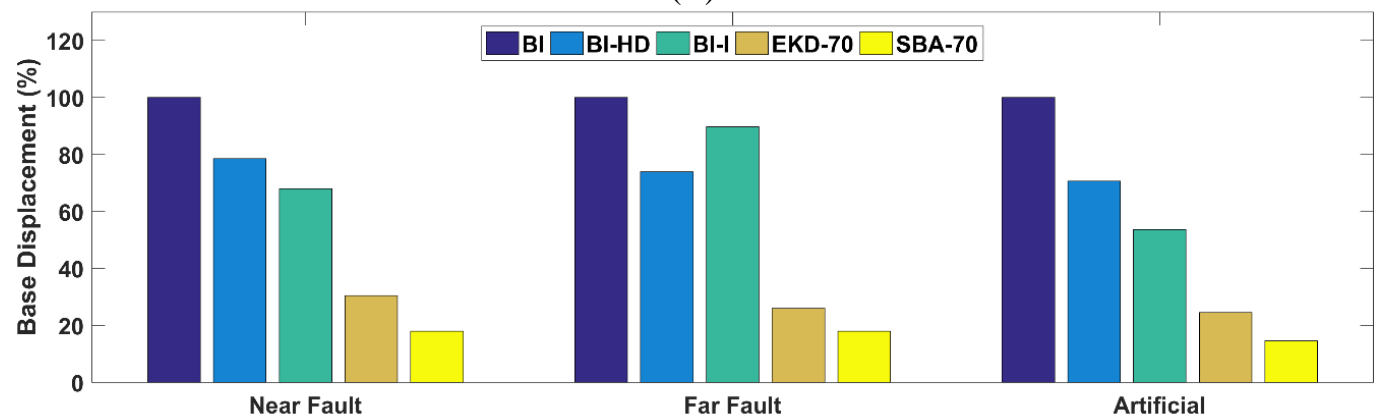

(D)

Figure 11. Dynamic responses of all the earthquake motions selected and all the considered systems, IN, BI, BI-HD, BI-I, EKD-70, and SBA-70. (A) top-floor acceleration, (B) $1^{\text {st }}$ floor drift, (C) base shear and (D) base displacement. 
In order to observe the efficiency of the proposed system, SBA, the results of the controlled structure are compared to other seismically protected structures. In particular: 1 ) a conventional base isolated structure with $\zeta_{B}=5 \%$ and $f_{B}=0.4$ $\mathrm{Hz}$ (BI), 2) a highly damped base isolated structure with an increased damping ratio of $20 \%$ (BI-HD), 3) a conventional base isolated structure equipped with an inerter (BI-I) and 4) a controlled structure with the extended KDamper implemented at the base of the structure, without the inerter (EKD, SBA with $b=0$ ).

Figure 11 presents the system main dynamic responses of all the examined control systems and considered earthquake excitations. It is observed that the SBA-70 manages to greatly reduce the superstructure dynamic behavior, retaining the base displacement drastically low (few centimeters). Comparative results: A) of the top floor absolute acceleration, (B) the total base shear and (C) the base relative displacement between the initial (IN), the conventional Base Isolated system (BI) and the SBA-70, are presented in Figure 12. The presented time histories relate to the Chi-Chi earthquake (1999).

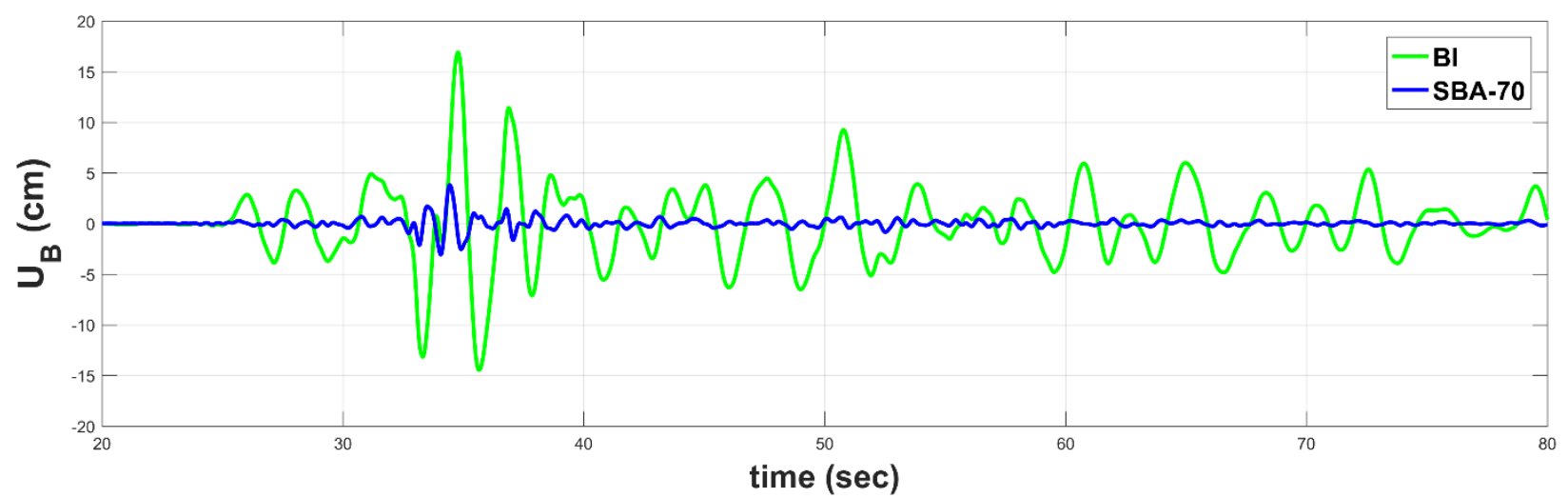

(A)

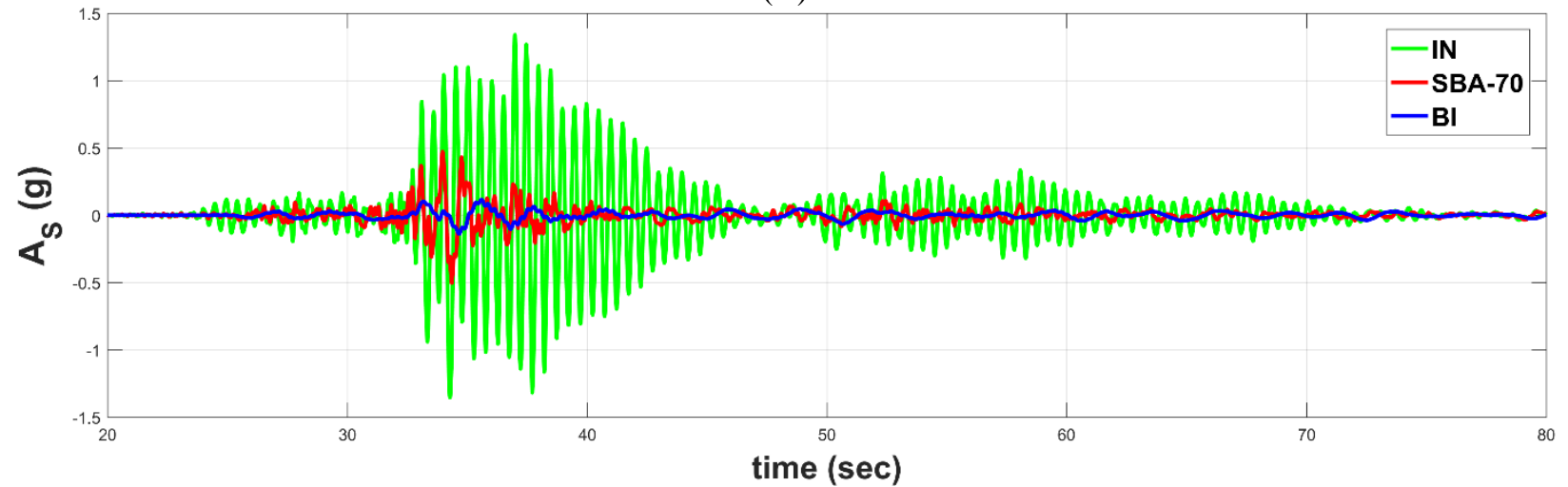

(B)

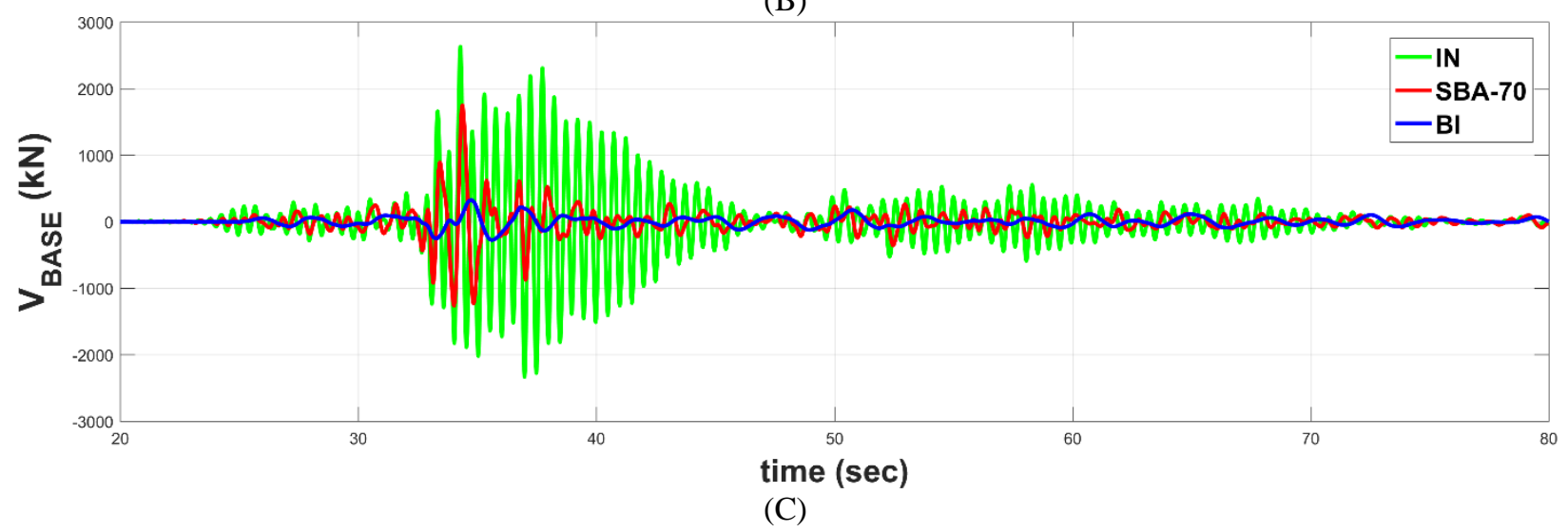

Figure 12. Comparative results, in terms of (A) base displacement $(\mathrm{cm}),(\mathrm{B})$ top floor absolute acceleration $(\mathrm{g})$ and (C) total base shear $(\mathrm{kN})$, between the IN, the BI and the SBA-70 system, for the Chi-Chi earthquake record (1999). 


\subsection{Sensitivity analysis and effects of detuning}

Once the optimal SBA parameters of a SDoF system have been derived in Section 3, the validity of the optimal design procedure is here assessed for a multistory building. To this aim, a sensitivity analysis is performed in which the SBA parameters are slightly varied from their actual optimal values found in the above optimization problem, in an attempt to assess to what extent, the dynamic response varies (degrades) accordingly. Time history analyses are performed with all the 30 artificial accelerograms generated according to section 3.2. Given the dynamic properties of the seismically protected building, and considering the SBA-70 set of optimized parameters, a 50\% variation (detuning) of the SBA free design variables is explored, i.e. the interval [0.5 - 1.5] $f_{0}, k_{N}, c_{U P}, c_{D O W N}, b$ and the additional mass $m_{D}$. For variation of each of these elements, the results of 30 time-history analyses are then averaged to obtain the mean values of a few response indicators, including: 1) top floor absolute acceleration $a_{S}, 2$ ) top floor displacement $\left.u_{\text {top }}, 3\right) 1^{\text {st }}$ floor drift, 4) base displacement $\left.u_{B}, 5\right) \mathrm{NS}$ element stroke $u_{B-D}$ and 6) total base shear $V_{B A S E}$. It is expected that as the SBA parameters depart from their optimal values, the effectiveness of the vibration control decreases accordingly. Relevant results, in terms of surface and contour plots of the top floor absolute acceleration $a_{S}, 1^{\text {st }}$ floor drift and base displacement $u_{B}$ are illustrated in Figures 13.A, B and C, respectively.

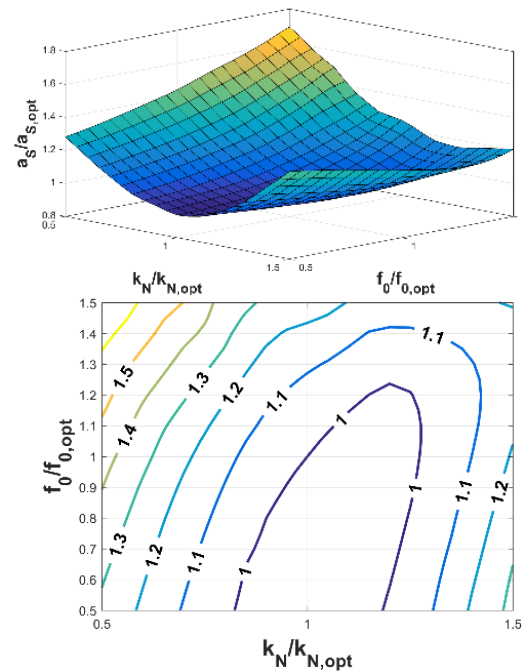

(A)

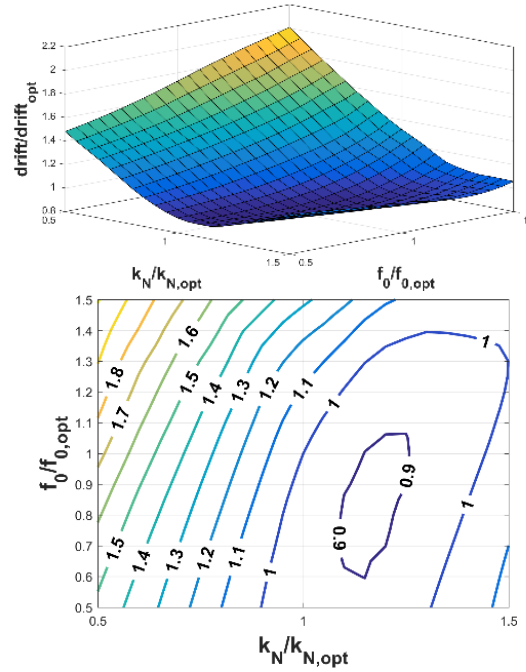

(B)

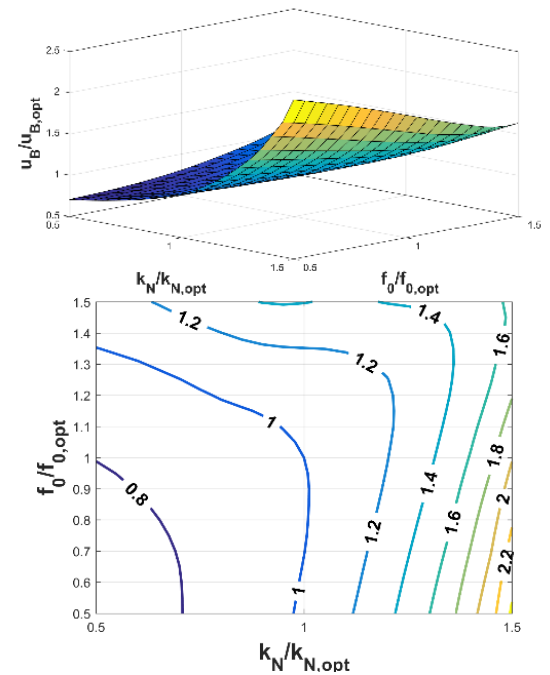

(C)

Figure 13. Sensitivity analysis and detuning effects of the top floor absolute acceleration (A), $1^{\text {st }}$ floor drift (B) and base displacement (C) by varying the free design variables $f_{0}$ and $k_{N}$ from their optimal values.

It can be seen that the optimal SBA parameters based on the SDoF assumption lead to very accurate results for the system response in terms of displacement and acceleration. Indeed, the minimum top floor absolute acceleration $a_{S}$, $1^{\text {st }}$ floor drift and base displacement $u_{B}$ are attained almost where the SBA parameters match the optimal values $f_{0}$ and $k_{N}$ obtained in section 3 (Figure 13). In Figure 14, the aforementioned response indicators are scrutinized by varying one SBA parameter one at a time, i.e. damping coefficients $c_{U P}, c_{D O W N}, b$, and $m_{D}$. It is observed that the detuning effects regarding the SBA parameters $c_{D O W N}$ and $m_{D}$ have lower influence than the variation of the $c_{U P}$ and $b$.

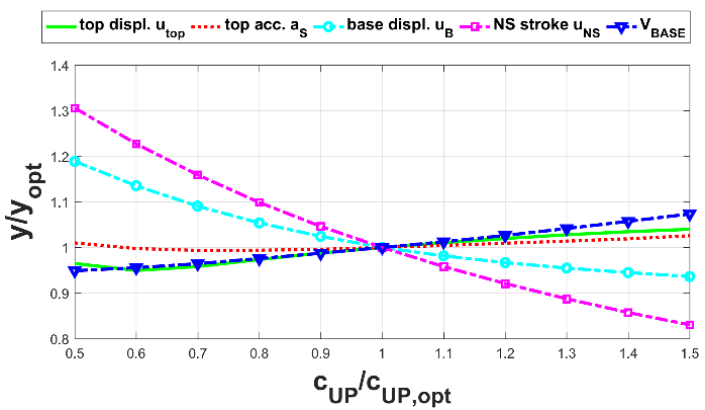

(A)

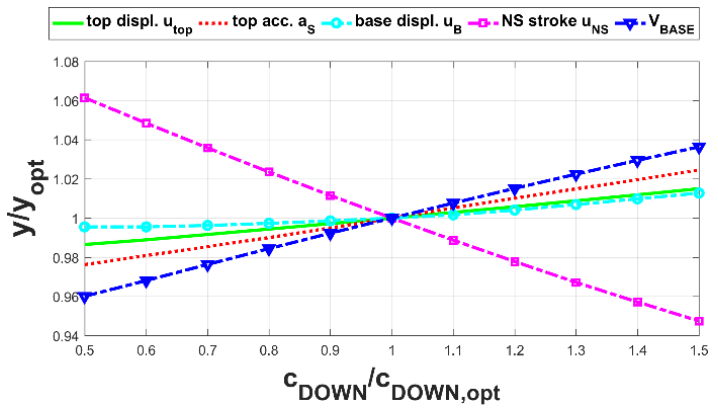

(B) 


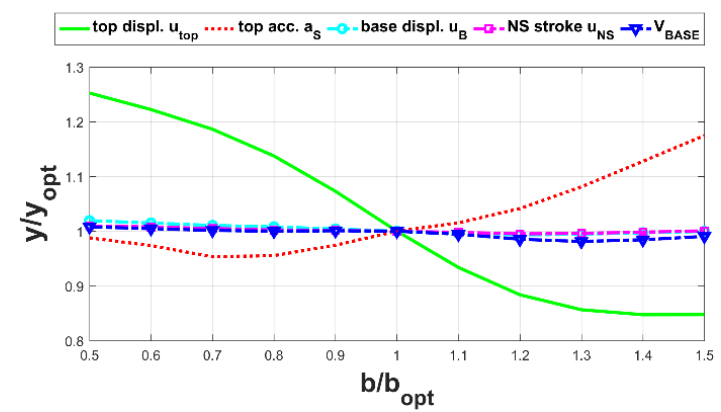

(C)

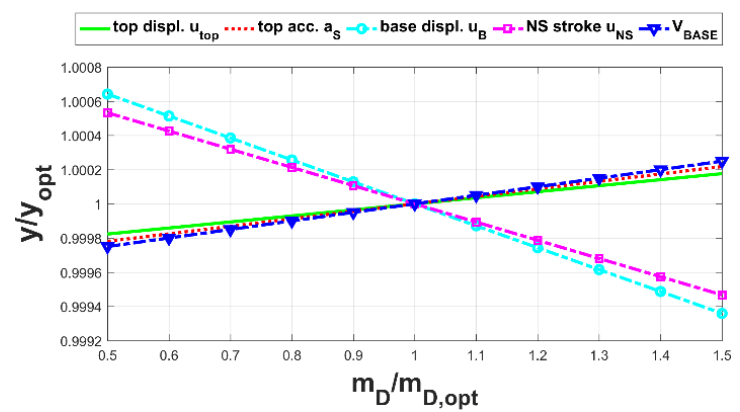

(D)

Figure 14. Sensitivity analysis and detuning effect of five response indicators, $u_{t o p}, a_{S}, u_{B}, u_{N S}$ and $V_{B A S E}$ by varying the SBA parameters: (A) $c_{U P}$, (B) $c_{D O W N},(\mathrm{C}) b$ and (D) $m_{D}$.

\section{INDICATIVE DESIGN OF SBA}

The selection of the NS element's set-up, as well as the positive stiffness elements, $k_{P S}$ and $k_{R}$, the artificial dampers $c_{U P}$ and $c_{D O W N}$ and the additional mass $m_{D}$, require the solution of the linear problem first in order to estimate the maximum absolute dynamic responses that are necessary for the design. More specifically, the base relative displacement $u_{B}$ relates to $k_{R}$, the NS element stroke $u_{B-D}$ relates to the NS element, the SBA relative displacement $u_{D}$ relates to $k_{P S}$. The SBA-70 set of optimized parameters, implemented in a 3-story building structure with a total superstructure mass of $300 \mathrm{tn}$, is considered. The maximum values of the dynamic responses needed for the design is: $\max \left|u_{B}\right|=0.0304 \mathrm{~m}, \max \left|u_{B-D}\right|=0.055 \mathrm{~m}$ and $\max \left|u_{D}\right|=0.0389 \mathrm{~m}$. The parameters of the (total) SBA-70 components are presented in Table 2. The implementation is realized using 4 SBA devices.

Table 2. SBA-70 set of optimized parameters.

\begin{tabular}{|c|c|c|c|c|c|c|c|c|c|}
\hline & $\begin{array}{c}f_{0}(H z) \\
\text { without } b\end{array}$ & $\begin{array}{c}f_{0}(H z) \\
\text { with } b\end{array}$ & $\begin{array}{c}k_{N S} \\
(k N / m)\end{array}$ & $\begin{array}{c}c_{U P} \\
(k N s / m)\end{array}$ & $\begin{array}{c}c_{D O W N} \\
(k N s / m)\end{array}$ & $\begin{array}{c}b \\
\left(\% m_{t o t}\right)\end{array}$ & $\begin{array}{c}m_{D} \\
\left(\% m_{t o t}\right)\end{array}$ & $\begin{array}{c}k_{P S} \\
(k N / m)\end{array}$ & $\begin{array}{c}k_{R} \\
(k N / m)\end{array}$ \\
\hline SBA-70 & 1.5 & 1.07 & -14287 & 564.2 & 394.1 & 97 & 0.1 & 24467 & 60996 \\
\hline
\end{tabular}

\subsection{NS element $k_{N S}$}

Regarding the realization of the NS element, the proposed configuration presented in section 4.2 is followed, with 9 conventional steel spiral spring implemented per device. In Table 3, the NS element entire set-up is presented, regarding the proposed configuration of the NS element for each one of the four SBA devices, with $k_{N S}=k_{N C}=(-$ $14287 / 4) / 9=-397 \mathrm{kN} / \mathrm{m}, U B=1.01, L B=0.9, u_{B-D}=u m a x=0.055 \mathrm{~m}$ and $c_{l}=-0.05$ (parameters regarding the NS element set up, [22]).

Table 3. NS element set-up for each SBA device.

\begin{tabular}{|c|c|c|c|c|}
\hline$k_{H}(\mathrm{kN} / \mathrm{m})$ & $l_{H I}(\mathrm{~m})$ & $a(m)$ & $d(\mathrm{~m})$ & $\mathrm{c}_{I}$ \\
\hline 421.9 & 0.256 & 0.0758 & 0.26 & -0.05 \\
\hline
\end{tabular}

\subsection{Damping coefficients $c_{U P}$ and $c_{D O W N}$}

The artificial dampers are realized with four parallel damping elements implemented per device. The damping coefficients are low, $c_{U P}=564.2 /\left(4^{*} 4\right)=35.26 \mathrm{kNs} / \mathrm{m}$ and $c_{D O W N}=394.1 /(4 * 4)=24.63 \mathrm{kNs} / \mathrm{m}$, therefore linear damping devices can be used, such as LD1110 from [40] catalog.

\subsection{Positive stiffness elements $k_{P S}$ and $k_{R}$}

The maximum design displacements for the stiffness elements $k_{P S}$ and $k_{R}$ is 3.89 and $3.04 \mathrm{~cm}$ respectively. Furthermore, the stiffness of these elements for each of the 4 SBA devices is: $k_{P S}=24467 / 4=6116.75 \mathrm{kN} / \mathrm{m}$ and $k_{R}=60996 / 4=15249 \mathrm{kN} / \mathrm{m}$. Therefore, the realization of the positive stiffness elements is possible in various ways, as for example, conventional steel spiral springs, simple elastomeric bearings (or any type of special bearings) or even conventional structural elements. For example, the realization of the $k_{P S}$ and $k_{R}$ with simple elastomeric bearings is 
possible with the SI-H550/56 and SI-H 1000/70 from the FIP Industriale elastomeric isolators catalog [41], with a designed maximum deformation of $10.0 \mathrm{~cm}$.

\subsection{Oscillating mass $m_{D}$}

The additional mass of each of the 4 SBA devices is realized with concrete, having $\rho_{m a t}=2400 \mathrm{~kg} / \mathrm{m}^{3}$. Assuming planar square top view with a height of $h_{S B A}=0.1 \mathrm{~m}$, the resulting dimension of the additional mass is:

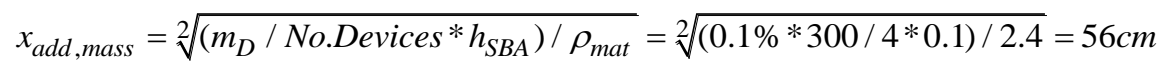

\section{CONCLUSIONS}

In this paper, a stiff seismic base absorber (SBA) is proposed, that combines an extension of the KDamper concept with an inerter device. The SBA is designed realistically and its optimal parameters are selected with engineering criteria. Proper constraints and limitations are posed on the free design variables and the system dynamic responses. The input ground motions are artificial accelerograms generated to be compatible with the EC8 acceleration response spectra. The SBA dynamic performance is examined also with real near and far fault earthquake records, and a realistic displacement-dependent configuration for the realization of the NS element is proposed. Subsequently, the SBA design is extended for implementation in multi-story building structures as a stiff seismic base absorber. The system parameters are selected from the previously stated optimization problem. A comparison with various base isolated systems (conventional, highly damped, equipped with Inerter or extended KDamper) is then made in order to prove the efficiency of the proposed stiff seismic base absorber, SBA. Based on the dynamic analysis and the results obtained, the following concluding remarks can be made:

1. The SBA is realistically designed, as it foresees variation in all stiffness elements (10\%) and assumes a small additional mass of $0.1 \%$

2. The optimal system parameters are selected based on engineering criteria with proper constraints and limitations to the system dynamic responses.

3. The SBA is designed according to the seismic design codes. More specifically, 30 artificial accelerograms are generated, designed to be compatible with the EC8 response spectra.

4. The NS element is realized with a displacement-dependent configuration, and the results of the non-linear system are proven to be equivalent to the initially solved linear one.

5. Based on the performed sensitivity analysis, the SBA is not vulnerable to detuning.

6. The SDoF system controlled with SBA manages to retain the structure absolute acceleration at acceptable levels, while at the same time the structure relative displacement is significantly low.

7. The superstructure dynamic behavior of the examined multi-story building controlled with SBA is greatly improved. More specifically, the floor accelerations and the inter-story drifts are significantly reduced, and at the same time, the base displacement is dramatically low, as compared to other base isolation approaches.

8. The small base displacement of the SBA with high $A F=70 \%$ (acceleration filter), renders the implementation of the proposed device feasible using conventional structural elements, without the need of special type of bearings. As a consequence, retrofitting is possible.

9. The design of the SBA devices is realistic and within reasonable technological capabilities.

\section{REFERENCES}

[1] Warn GP, Ryan KL. A Review of Seismic Isolation for Buildings: Historical Development and Research Needs. Buildings 2012;2:300-25. doi:10.3390/buildings2030300.

[2] Reggio A, Angelis M De. Optimal energy-based seismic design of non-conventional Tuned Mass Damper (TMD) implemented via inter-story isolation. Earthq Eng Struct Dyn 2015;44:1623-42. doi:10.1002/eqe. 2548 .

[3] Kunde MC, Jangid RS. Seismic behavior of isolated bridges: A-state-of-the-art review. vol. 3. 2003.

[4] De Angelis M, Giannini R, Paolacci F. Experimental investigation on the seismic response of a steel liquid storage tank equipped with floating roof by shaking table tests. Earthq Eng Struct Dyn 2009:n/a-n/a. doi:10.1002/eqe.945. 
[5] Paolacci F, Giannini R, De Angelis M. Seismic response mitigation of chemical plant components by passive control techniques. J Loss Prev Process Ind 2013;26:924-35. doi:10.1016/j.jlp.2013.03.003.

[6] Whittaker AS, Kumar M, Kumar M. Seismic isolation of nuclear power plants. Nucl Eng Technol 2014;46:569-80. doi:10.5516/NET.09.2014.715.

[7] Taniguchi T, Der Kiureghian A, Melkumyan M. Effect of tuned mass damper on displacement demand of base-isolated structures. Eng Struct 2008;30:3478-88. doi:10.1016/j.engstruct.2008.05.027.

[8] Xiang P, Nishitani A. Optimum design for more effective tuned mass damper system and its application to base-isolated buildings. Struct Control Heal Monit 2014;21:98-114. doi:10.1002/stc.1556.

[9] Hashimoto T, Fujita K, Tsuji M, Takewaki I. Innovative base-isolated building with large mass-ratio TMD at basement for greater earthquake resilience. Futur Cities Environ 2015. doi:10.1186/s40984-015-0007-6.

[10] Wang J-F, Lin C-C, Lian C-H. Two-stage optimum design of tuned mass dampers with consideration of stroke. Struct Control Heal Monit 2009;16:55-72. doi:10.1002/stc.312.

[11] De Domenico D, Ricciardi G. An enhanced base isolation system equipped with optimal tuned mass damper inerter (TMDI). Earthq Eng Struct Dyn 2018;47:1169-92. doi:10.1002/eqe.3011.

[12] Lazar IF, Neild SA, Wagg DJ. Using an inerter-based device for structural vibration suppression. Earthq Eng Struct Dyn 2014. doi:10.1002/eqe.2390.

[13] Smith MC. Synthesis of Mechanical Networks: The Inerter. IEEE Trans Automat Contr 2002;47. doi:10.1109/TAC.2002.803532.

[14] Carrella A, Brennan MJ, Waters TP. Static analysis of a passive vibration isolator with quasi-zero-stiffness characteristic. J Sound Vib 2007;301:678-89. doi:10.1016/j.jsv.2006.10.011.

[15] DeSalvo R. Passive, Nonlinear, Mechanical Structures for Seismic Attenuation. J Comput Nonlinear Dyn 2007;2:290. doi:10.1115/1.2754305.

[16] Iemura $\mathrm{H}$, Pradono MH. Advances in the development of pseudo-negative-stiffness dampers for seismic response control. Struct Control Heal Monit 2009;16:784-99. doi:10.1002/stc.345.

[17] Pasala DTR, Sarlis AA, Nagarajaiah S, Reinhorn AM, Constantinou MC, Taylor D. Adaptive Negative Stiffness: New Structural Modification Approach for Seismic Protection. J Struct Eng 2013;139:1112-23. doi:10.1061/(ASCE)ST.1943-541X.0000615.

[18] Sun T, Lai Z, Nagarajaiah S, Li HN. Negative stiffness device for seismic protection of smart base isolated benchmark building. Struct Control Heal Monit 2017. doi:10.1002/stc.1968.

[19] Shen Y, Peng H, Li X, Yang S. Analytically optimal parameters of dynamic vibration absorber with negative stiffness. Mech Syst Signal Process 2017. doi:10.1016/j.ymssp.2016.08.018.

[20] Wang M, Sun F fei, Yang J qi, Nagarajaiah S. Seismic protection of SDOF systems with a negative stiffness amplifying damper. Eng Struct 2019. doi:10.1016/j.engstruct.2019.03.110.

[21] Wang M, Sun F, Nagarajaiah S. Simplified optimal design of MDOF structures with negative stiffness amplifying dampers based on effective damping. Struct Des Tall Spec Build 2019. doi:10.1002/tal.1664.

[22] Antoniadis IA, Kanarachos SA, Gryllias K, Sapountzakis IE. KDamping: A stiffness based vibration absorption concept. JVC/Journal Vib Control 2018;24:588-606. doi:10.1177/1077546316646514.

[23] Antoniadis I.A., Kapasakalis, K.A., Sapountzakis EJ. Isolation or Damping? A Soil-dependent approach based on the KDamper concept. Proc. 2nd Int. Conf. Nat. Hazards Infrastruct. (ICONHIC 2019), 2019.

[24] Sapountzakis, E.J., Kapasakalis, K.A. AIA. Negative Stiffness Elements in Seismic Isolation of Bridges. Proc. 2nd Int. Conf. Nat. Hazards Infrastruct. (ICONHIC 2019), 2019.

[25] Kapasakalis KA, Alamir CHT, Antoniadis IA, Sapountzakis EJ. Frequency Base Design of the KDamper Concept for Seismic Isolation of Bridges. Proc. 14th Int. Conf. Vib. Probl. (ICOVP 2019), 2019.

[26] Bollano, P-O.N., Kapasakalis, K.A., Sapountzakis, E.J. AIA. Design and Optimization of the KDamper Concept for Seismic Protection of Bridges. Proc. 14th Int. Conf. Vib. Probl. (ICOVP 2019), 2019. 
[27] Kapasakalis, K.A., Antoniadis I.A. SAE. Implementation of the KDamper Concept for Seismic Protection of Bridges. Proc. 14th Int. Conf. Vib. Probl. (ICOVP 2019), 2019.

[28] Kapasakalis, K.A., Sapountzakis, E.J., Antoniadis IA. Implementation of the KDamper Concept to Wind Turbine Towers. Proc. 6th Int. Conf. Comput. Methods Struct. Dyn. Earthq. Eng. (COMPDYN 2017), 2017.

[29] Kapasakalis, K.A., Sapountzakis, E.J., Antoniadis IA. Optimal Design of the KDamper Concept for Structures on Compliant Supports. Proc. 16th Eur. Conf. Earthq. Eng. (16ECEE 2018), 2018.

[30] Kapasakalis, K.A., Sapountzakis, E.J., Antoniadis IA. KDamper Concept in Seismic Isolation of Multi Storey Building Structures. Proc. 9th GRACM Int. Congr. Comput. Mech. (9GRACM 2018), 2018.

[31] Kapasakalis, K.A., Sapountzakis, E.J., Antoniadis IA. Kdamper concept in seismic isolation of building structures with soil structure interaction. Proc. 13th Int. Conf. Comput. Struct. Technol., 2018.

[32] Kapasakalis, K.A., Antoniadis, I.A., Sapountzakis EJ. Control of Multi Storey Building Structures with a New Passive Vibration Control System Com-bining Base Isolation with KDamper. Proc. 7th Int. Conf. Comput. Methods Struct. Dyn. Earthq. Eng. (COMPDYN 2019), 2019.

[33] Kapasakalis, K.A., Antoniadis, I.A., Sapountzakis EJ. Implementation of the KDamper Concept for Base Isolation to a Typical Concrete Building Structure. Proc. 12th Int. Congr. Mech., 2019.

[34] Kapasakalis, K.A., Antoniadis, I.A. SEJ. KDamper Concept for Base Isolation and Damping of High-Rise Building Structures. Proc. 14th Int. Conf. Vib. Probl. (ICOVP 2019), 2019.

[35] Antoniadis, I.A., Kapasakalis, K.A., Sapountzakis EJ. Advanced Negative Stiffness Absorbers for the Seismic Protection of Structures. Proc. Int. Conf. Key Enabling Technol. 2019, 2019. doi:https://doi.org/10.1063/1.5123704.

[36] Kapasakalis, K.A., Antoniadis, I.A, Sapountzakis EJ. Novel Vibration Absorption Systems with Negative Stiffness Elements for the Seismic Protection of Structures. 4th Natl. Conf. Earthq. Eng. Eng. Seismol. (Hellenic Assoc. Earthq. Eng. - HAEE / ETAM), 2019.

[37] Kapasakalis, K.A., Antoniadis, I.A., Sapountzakis EJ. Performance Assessment of the KDamper as a Seismic Absorption Base. Struct Control Heal Monit 2019. doi:10.1002/stc.2482.

[38] Zong Woo Geem, Joong Hoon Kim, Loganathan GV. A New Heuristic Optimization Algorithm: Harmony Search. Simulation 2001;76:60-8. doi:10.1177/003754970107600201.

[39] Seismosoft [2018]. SeismoArtif - A computer program for generating artificial earthquake accelerograms matched to a specific target response spectrum 2018. http://www.seismosoft.com.

[40] Fluid Viscous Dampers | Seismic Dampers | ITT Infrastructure | ITT Enidine n.d. https://www.ittinfrastructure.com/en-US/Products/Viscous-Dampers/ (accessed January 22, 2020).

[41] Elastomeric isolators https://www.fipindustriale.it/index.php?area=106\&menu=67\&lingua=1 (accessed January 22, 2020). 